\title{
Debunking the Myth: Do Maternal-Fetal Medicine Fellows Negatively Impact Resident Obstetrical Skills?
}

\author{
Sarah K. Dotters-Katz, MD, MMHPE ${ }^{1}$ Matthew Grace, MD ${ }^{2} \quad$ R Phillips Heine, MD ${ }^{3}$ Katie Propst, MD 4
}

${ }^{1}$ Department of Obstetrics and Gynecology, Duke University, Durham, North Carolina

Address for correspondence Sarah Dotters-Katz, MD, Department of

2 Department of Obstetrics and Gynecology, Vanderbilt University, Obstetrics and Gynecology, Duke Maternal Fetal Medicine, 2608 Erwin Nashville, Tennessee

${ }^{3}$ Department of Obstetrics and Gynecology, Wake Forest University, Winston-Salem, North Carolina

${ }^{4}$ Department of Obstetrics and Gynecology, Obstetrics/Gynecology and Women's Health Institute, Cleveland Clinic, Cleveland, Ohio

Am J Perinatol Rep 2020;10:e319-e323.

\begin{abstract}
Keywords

- MFM fellow

- fellowship

- medical education

- complex obstetrics

- resident education

Objective Residency applicants often express concern that fellows negatively impact surgical opportunities, especially with less common procedures. We sought to describe the impact of maternal-fetal medicine (MFM) fellows on resident surgical opportunities.

Study Design Anonymous 27-question e-survey sent to obstetrics and gynecology (OBGYN) residents in the United States and Puerto Rico in March 2018. Questions included experience as primary surgeon, for fourth year residents only, comfort performing procedures postresidency, and demographics. Residents from programs with MFM fellows (pMFM) were compared with those without (nMFM). Descriptive statistics used as appropriate. Regression was performed, controlling for significant variables.

Results A total of 417 residents completed the survey; 275 (66\%) from nMFM and 142 (33\%) from pMFM. PMFM residents were more likely to have $>7$ residents/year, be from an academic residency, and less likely to be planning to practice obstetrics postresidency (all, $p<0.01$ ). Plan to pursue MFM fellowship did not differ. NMFM residents were more likely to have been primary surgeon on a vacuum assisted delivery (77 vs. $63 \%, p<0.01$ ). No difference in primary surgeon experience was seen for forceps delivery, breech deliveries, third- or fourth-degree repairs, cerclage, or cesarean hysterectomy. With regard to comfort performing procedures postresidency, vacuum-assisted vaginal delivery (VAVD) was more likely among nMFM trainees, no other differences seen. In regression models, no differences in likelihood of comfort performing procedures postresidency for any procedures based on the presence of MFM fellows were seen. Among pMFM residents, 94\% stated fellows positively impacted their learning.

Conclusion MFM fellows do not appear to impact residents' perceived competency in obstetric procedures and the majority of trainees report that fellows positively impact their education.
\end{abstract}

received

February 5, 2020

accepted

April 24, 2020
DOI https://doi.org/

10.1055/s-0040-1715168. ISSN 2157-6998.
Copyright $\odot 2020$ by Thieme Medical Publishers, Inc., 333 Seventh Avenue, New York, NY 10001, USA. Tel: +1(212) 760-0888.
License terms

(요 (1) $\Theta \circledast$ 
Many factors contribute to a medical student's preferences in selection of obstetrics and gynecology (OBGYN) residency program. One common concern is that the presence of fellows will negatively impact education, specifically related to surgical experiences and procedural skills. Students may be concerned that fellows may "steal" the less common or more complicated procedures, leading to a decrease in their own surgical volume and inhibiting their learning. The literature is limited and mixed on this topic. While some data support these concerns, ${ }^{1,2}$ one study suggests that the presence of urogynecology fellows does not impact resident confidence with urogynecology procedures. $^{3}$ Similarly, for gynecologic oncology procedures, presence of fellows did not impact self-reported proficiency in radical hysterectomy and lymphadenectomy. ${ }^{4}$ No data exist regarding the impact of maternal-fetal medicine (MFM) fellows on resident confidence with obstetrical procedures. However, unlike a radical hysterectomy or a lymphadenectomy, which are only done by a subspecialist, most complex obstetric procedures are performed by general obstetricians.

Core procedures, as outlined by the 11th edition of the Council of Resident Education in Obstetrics and Gynecology (CREOG) objectives, are those procedures which an individual who is graduating from OBGYN training should understand and be able to perform independently, regardless of postresidency plan. ${ }^{5}$ These procedures include, but are not limited to, forcepsassisted vaginal delivery (FAVD), vacuum-assisted vaginal delivery (VAVD), vaginal cerclage, repair of third-degree lacerations, repair of fourth-degree lacerations, breech extraction of a second twin, breech vaginal delivery, and cesarean hysterectomy. The Accreditation Council for Graduate Medical Education (ACGME) also lists these procedures as level 4 in the obstetric technical skills in the OBGYN milestones from. ${ }^{6}$

Thus, in contrast to many urogynecology and gynecologic onocology procedures, resident experience and skills in complex obstetrics is critical for future practice. As noted, limited data exist regarding impact of fellows on resident opportunities with these procedures. Thus, we sought assess the impact of MFM fellows on resident opportunities and resultant perceived confidence among residents with complex obstetric procedures.

\section{Methods}

We performed a cross-sectional study of OBGYN residents in the United States and Puerto Rico during the 2017 to 2018 academic year. This study was deemed exempt by the institutional review board (IRB: Pro00090727). An anonymous electronic survey was developed based on a prior analogous survey used by Propst et al and Schimpf et al to describe resident experience in urogynecology but was adapted for obstetrics.,7 The survey was then edited for clarity and content by a team of subject matter experts in MFM, as well as a team of subject matter experts, in medical education. After edits, a pilot survey was sent to local MFM fellows and local residents, to obtain feedback on question clarity and necessity. The final survey contained of 27 questions, including demographic data, future career trajectory, and experiences with complex obstetrics.
An anonymous survey link was sent in March 2018, via the CREOG coordinator listserv, with a request for distribution to their OBGYN residents. A reminder e-mail was resent through the CREOG coordinator listserv 2 weeks later. All current residents in the United States and Puerto Rico were eligible to participate. Participants who completed the survey could elect to submit their e-mail through a separate survey link (that was not connected to the primary survey) to enter a drawing for an Amazon Gift card. March was specifically selected due to the late time in the year, to ensure adequate time for participation in obstetric procedures.

The presence of MFM fellows was delineated by resident report within the survey. The CREOG 11 th edition objectives and the ACGME milestones were used to define the complex obstetric procedures. Based on these two documents, complex obstetric procedures were defined as FAVD, VAVD, vaginal cerclage, breech second twin, breech vaginal delivery, third and 4th degree perineal repairs and cesarean hysterectomy. Also, we were interested in comfort level with cesarean delivery for a patient with body mass index $(\mathrm{BMI})>50 \mathrm{~kg} / \mathrm{m}^{2}$. Respondents were asked in a yes/no manner if they had been the primary surgeon on the above procedures and if they were comfortable performing these procedures independently. Respondents in their fourth year of training were also asked if they would feel comfortable performing these procedures postresidency. Information about program type, program size, number and type of fellowships present, residency year, and gender was also ascertained.

Comfort performing complex obstetric procedures after graduation from residency was the primary outcome. Experiences as primary surgeon and comfort performing independently were also assessed. Given the complexity of these procedures (milestone level 4), it would be uncommon for an intern (postgraduate year [PGY] 1) or second year (PGY2) resident to feel comfortable to perform these independently. Thus, when analyzing comfort while performing independently, only third (PGY3) and fourth year (PGY4) respondents were included. As noted above, only PGY4 residents were asked about comfort performing postresidency; thus only PGY4s were included in this analysis. Residents who self-identified as having MFM fellows present at their training program (pMFM) were compared with those who did not have MFM fellows present (nMFM).

Operative vaginal delivery was defined as either FAVD or VAVD. A large residency program size was defined as eight or more residents a year. Long-MFM exposure was defined as 6 or more months of specific-MFM time in residency, which was at or above the $75 \%$ for the study population. Survey completion rate was defined as total complete responses/ total number of surveys started. Noncompleted surveys were excluded.

Data were analyzed using simple statistics as appropriate with Fisher's exact, Chi-square tests for categorical variables, and Kruskal-Wallis or $t$-test for continuous variables. STATA (version 14.0, College Station, TX) was used. Significance was defined as $p$-value of $<0.05$ for the primary analysis. Regression performed to assess adjusted odds of outcomes and control for confounders. 
Table 1 Demographic data

\begin{tabular}{|l|l|l|l|}
\hline Demographic & $\begin{array}{l}\text { MFM fellows } \\
\text { present } \\
\boldsymbol{n}=\mathbf{1 4 2}(\%)\end{array}$ & $\begin{array}{l}\text { No MFM } \\
\text { fellows } \\
\boldsymbol{n}=\mathbf{2 7 5}(\%)\end{array}$ & $p$-Value \\
\hline Age 26-30 (y) & $97(68)$ & $198(72)$ & 0.61 \\
\hline Female gender & $125(88)$ & $242(88)$ & 0.99 \\
\hline $\begin{array}{l}\text { Upper level resident } \\
\text { (PGY3 and 4) }\end{array}$ & $60(42)$ & $142(55)$ & 0.07 \\
\hline $\begin{array}{l}\text { Big program } \\
\text { (>7 residents/year) }\end{array}$ & $95(67)$ & $72(26)$ & $<0.01$ \\
\hline Academic residency & $124(87)$ & $184(67)$ & $<0.01$ \\
\hline $\begin{array}{l}\text { Dedicated } \\
\text { MFM rotation }\end{array}$ & $129(91)$ & $259(9)$ & 0.09 \\
\hline $\begin{array}{l}\text { Median months } \\
\text { of MFM (IQR) }\end{array}$ & $3(2-6)$ & $4(3-6)$ & $<0.01$ \\
\hline Plan to practice OB & $75(53)$ & $183(67)$ & $<0.01$ \\
\hline Plan MFM fellowship & $18(13)$ & $24(9)$ & 0.20 \\
\hline
\end{tabular}

Abbreviations: IQR, interquartile range; MFM, maternal-fetal medicine; $\mathrm{OB}$, obstetrics; $\mathrm{PGY}$, postgraduation year.

Note: all data are $n(\%)$, unless otherwise noted.

\section{Results}

Four hundred and seventeen residents completed the survey; with a completion rate of $96.5 \%$ (417/432). There was approximately equal distribution among all four residency years (data not shown). Sixty-six percent $(n=275)$ of respondents were from nMFM and 33\% $(n=142)$ from pMFM. PMFM respondents were more likely to have $>7$ residents/year, be from an academic residency, and less likely to be planning to practice obstetrics postresidency ( - Table 1, all $p<0.01$ ). Plan to pursue MFM fellowship did not differ ( - Table 1 ).

When considering all residents, PGY1-4, nMFM residents were more likely to have been primary surgeon on a VAVD (77 vs. $63 \%, p<0.01$ ). No difference in primary surgeon experience was seen for FAVD, (48 vs. $57 \%, p=0.09$ ), breech deliveries, third- or fourth-degree laceration repairs, cerclage, or cesarean hysterectomy (-Table 2). Among residents in PGY3 and 4, pMFM residents were more likely to feel comfortable with breech extraction of a second twin (48 vs. $33 \%, p=0.04$ ). Comfort levels with other procedures did not differ ( - Table 3 ).

With regard to comfort performing procedures postresidency, those from nMFM were more likely to feel comfortable with VAVD compared with pMFM (100 vs. $87 \%, p=0.01$ ). There was no difference in comfort performing FAVD postresidency based on presence of MFM fellows. All graduating PGY4s felt comfortable performing at least one form of operative vaginal delivery (either VAVD or FAVD; - Table 4). No differences in postresidency comfort was seen for any other procedures (-Table 4). After controlling for program size, plan to practice obstetrics postresidency, and academic programs, no differences existed in likelihood of comfort performing procedures postresidency for any procedures based on the presence of MFM fellows (-Table 5). Because all nMFM respondents were comfortable with VAVD postresidency, regression models could not be run. Of note, among pMFM residents, 94\% stated fellows positively impacted their learning.
Table 2 Resident as primary surgeon by presence of MFM fellows (includes PGY1-4)

\begin{tabular}{|l|l|l|l|}
\hline Procedure & $\begin{array}{l}\text { MFM fellows } \\
\text { present } \\
\boldsymbol{n}=\mathbf{1 4 2}(\%)\end{array}$ & $\begin{array}{l}\text { No MFM } \\
\text { fellows } \\
\boldsymbol{n}=\mathbf{2 7 5}(\%)\end{array}$ & $p$-Value \\
\hline VAVD & $85(63)$ & $201(77)$ & $<0.01$ \\
\hline FAVD & $76(57)$ & $125(48)$ & 0.09 \\
\hline Any OVD & $95(67)$ & $204(74)$ & 0.12 \\
\hline Cerclage & $79(59)$ & $166(63)$ & 0.39 \\
\hline Breech extraction & $50(37)$ & $86(33)$ & 0.37 \\
\hline $\begin{array}{l}\text { Breech vaginal } \\
\text { delivery }\end{array}$ & $22(16)$ & $59(23)$ & 0.14 \\
\hline $\begin{array}{l}\text { 4th-degree } \\
\text { perineal repair }\end{array}$ & $47(36)$ & $97(37)$ & 0.78 \\
\hline $\begin{array}{l}\text { 3rd-degree } \\
\text { perineal repair }\end{array}$ & $34(25)$ & $65(25)$ & 0.90 \\
\hline $\begin{array}{l}\text { Cesarean delivery } \\
\text { on BMI > 50 kg/m² }\end{array}$ & $116(8)$ & $234(89)$ & 0.42 \\
\hline Cesarean hysterectomy & $25(19)$ & $60(23)$ & 0.33 \\
\hline
\end{tabular}

Abbreviations: BMI, body mass index; FAVD, forceps-assisted vaginal delivery; MFM, maternal-fetal medicine; OVD, operative vaginal delivery; PGY, postgraduation year; VAVD, vacuum-assisted vaginal delivery.

Table 3 Comfortable performing independently (among $\mathrm{PGY3}+4)$

\begin{tabular}{|l|l|l|l|}
\hline Procedure & $\begin{array}{l}\text { MFM fellows } \\
\text { present } \\
\boldsymbol{n}=\mathbf{6 0}(\%)\end{array}$ & $\begin{array}{l}\text { No MFM } \\
\text { fellows } \\
\boldsymbol{n}=\mathbf{1 4 2}(\%)\end{array}$ & p-Value \\
\hline VAVD & $49(82)$ & $120(85)$ & 0.62 \\
\hline FAVD & $25(42)$ & $43(30)$ & 0.12 \\
\hline Any OVD & $55(95)$ & $120(85)$ & 0.17 \\
\hline Cerclage & $38(63)$ & $91(64)$ & 0.92 \\
\hline Breech extraction & $29(48)$ & $47(33)$ & 0.04 \\
\hline $\begin{array}{l}\text { Breech vaginal } \\
\text { delivery }\end{array}$ & $8(13)$ & $19(13)$ & 0.99 \\
\hline $\begin{array}{l}\text { 4th-degree } \\
\text { perineal repair }\end{array}$ & $28(47)$ & $53(37)$ & 0.22 \\
\hline $\begin{array}{l}\text { 3th-degree } \\
\text { perineal repair }\end{array}$ & $54(90)$ & $115(81)$ & 0.11 \\
\hline $\begin{array}{l}\text { Cesarean delivery } \\
\text { on BMI > 50 kg/m }\end{array}$ & $57(9)$ & $126(89)$ & 0.16 \\
\hline Cesarean hysterectomy & $13(22)$ & $35(25)$ & 0.65 \\
\hline
\end{tabular}

Abbreviations: BMI, body mass index; FAVD, forceps-assisted vaginal delivery; MFM, maternal-fetal medicine; OVD, operative vaginal delivery; PGY, postgraduation year; VAVD, vacuum-assisted vaginal delivery.

\section{Discussion}

In this study, over 400 OBGYN residents experienced as a primary surgeon with VAVD and comfortable in performing VAVD independently were higher among nMFM residents. Otherwise, no differences were noted between trainees' comfort levels with complex obstetric procedures between nMFM and pMFM programs. In other words, the presence of 
Table 4 Procedures that residents would feel comfortable performing in practice (after graduation, includes only PGY4)

\begin{tabular}{|l|l|l|l|}
\hline Procedure & $\begin{array}{l}\text { MFM fellows } \\
\text { present } \\
\mathbf{n = 3 1}(\%)\end{array}$ & $\begin{array}{l}\text { No MFM } \\
\text { fellows } \\
\mathbf{n = 6 4}(\%)\end{array}$ & $p$-Value \\
\hline VAVD & $27(87)$ & $64(100)$ & 0.01 \\
\hline FAVD & $21(68)$ & $35(56)$ & 0.28 \\
\hline Any OVD & $31(100)$ & $64(100)$ & $>0.99$ \\
\hline Cerclage & $24(80)$ & $51(81)$ & $>0.99$ \\
\hline Breech extraction & $24(80)$ & $44(69)$ & 0.47 \\
\hline $\begin{array}{l}\text { Breech vaginal } \\
\text { delivery }\end{array}$ & $7(23)$ & $17(27)$ & 0.80 \\
\hline $\begin{array}{l}4 \text { th-degree } \\
\text { perineal repair }\end{array}$ & $27(87)$ & $50(81)$ & 0.57 \\
\hline $\begin{array}{l}3^{\text {rd }} \text {-degree } \\
\text { perineal repair }\end{array}$ & $31(100)$ & $61(95)$ & 0.55 \\
\hline $\begin{array}{l}\text { Cesarean delivery } \\
\text { on BMI }>50 \mathrm{~kg} / \mathrm{m}^{2}\end{array}$ & $31(100)$ & $63(98)$ & $>0.99$ \\
\hline Cesarean hysterectomy & $20(67)$ & $42(67)$ & $>0.99$ \\
\hline
\end{tabular}

Abbreviations: BMI, body mass index; FAVD, forceps-assisted vaginal delivery; MFM, maternal-fetal medicine; OVD, operative vaginal delivery; PGY, postgraduation year; VAVD, vacuum-assisted vaginal delivery.

Table 5 Odds and adjusted odds ratios for procedures that residents would feel comfortable performing in practice after graduation (includes only PGY4, no fellows as referent group) ${ }^{a}$

\begin{tabular}{|l|l|l|}
\hline Procedure & Odds ratio (95\% CI) & aOR (95\% CI) \\
\hline FAVD & $1.68(0.68-4.14)$ & $2.69(0.33-21.9)$ \\
\hline Cerclage & $0.96(0.32-2.86)$ & $1.39(0.23-8.49)$ \\
\hline $\begin{array}{l}\text { Breech } \\
\text { extraction }\end{array}$ & $1.56(0.58-4.21)$ & $2.17(0.31-15.1)$ \\
\hline $\begin{array}{l}\text { Breech vaginal } \\
\text { delivery }\end{array}$ & $0.89(0.33-2.35)$ & $1.04(0.24-4.51)$ \\
\hline $\begin{array}{l}\text { 4th-degree } \\
\text { perineal repair }\end{array}$ & $1.56(0.46-5.29)$ & $2.41(0.37-15.8)$ \\
\hline Cesarean hysterectomy & $1.02(0.41-2.56)$ & $1.30(0281-5.97)$ \\
\hline
\end{tabular}

Abbreviations: aOR, adjusted odds ratio; $\mathrm{Cl}$, confidence interval; FAVD, forceps-assisted vaginal delivery; PGY, postgraduation year

${ }^{a}$ Controlled for program size $>7$ residents/year, plan to practice obstetric postresidency, total months of maternal-fetal medicine and academic programs.

MFM fellows does not appear to impact residents' anticipated comfort level in performing complex obstetric procedures after graduation, even after controlling for confounders.

Declining surgical volume in training programs is well documented and obstetrics is no exception. Nationally, the number of twin vaginal deliveries and operative vaginal deliveries is decreasing. ${ }^{8}$ Thus, concerns from undergraduate medical learners and OBGYN trainees regarding exposure and experiences with these and other obstetric procedures are warranted. These concerns are also faced outside of OBGYN. However, it is reassuring that among urology and general surgery trainees, the presence of fellows has been shown to have minimal impact on resident surgical experiences. ${ }^{9,10}$ In emergency medicine, programs with fellowship have actually increased resident procedural numbers. ${ }^{11}$ Within our own field, Propst et al also noted this to be true when urogynecology fellows were present. ${ }^{3}$ Data from this study suggest similarly that obstetric surgical experiences are also not impacted by presence of MFM fellows.

The impact of fellows on resident education also is important. Fellows are closest in age and training to medical learners and are often quite clinically active, thus their frequent interactions with learners are in a unique position to have an important and immediate impact on our trainees. In a study on the impact neonatology fellows, $87.5 \%$ of resident respondents described fellows as a very important part of their education. ${ }^{12}$ Schimpf et al, in a survey of urogynecology education, noted that approximately $50 \%$ of resident respondents felt that urogynecology fellows positively impacted their education. ${ }^{7}$ More recently, Propst et al performed a similar study, noting that nearly $80 \%$ of resident respondents felt that urogynecology fellows positively influenced their education. ${ }^{3}$ In our study, residents from pMFM programs related an overwhelmingly positive impact of fellows in their training (>90\%).

Strengths of this study include that the subject matter is novel for our field and is critically important as we move forward with the responsibility of adequately training both residents and fellows. Additionally, the use of CREOG objectives and ACGME milestones are effective anchors to help identify the appropriate resident skills levels. Additionally, though no validated tool in obstetric skills exists, survey itself was derived from survey used by two separate authors in the urogynecology literature. ${ }^{3,7}$ Also, the makeup of our respondent group diverse, from a large variety of residency sizes, a mix of academic and nonacademic, and represented all ACOG regions.

\section{Limitations}

However, our study is not without limitations. First, responses are all self-reported and we have no way to corroborate resident statements of experience as primary surgeon. Similarly, we asked about resident comfort performing these procedures independently, as well as comfort performing postresidency; there is no way to assess actual surgical skills or competency based on these responses. We also cannot comment on the experiences and skills of residents at both nMFM and pMFM programs who did not respond to the survey. Similarly, impact of obstetric volume is another factor that we did not assess in our survey that might impact resident experience. However, residency size is based somewhat by obstetric volume, thus this variable could serve as a sort of proxy for obstetric volume, as we controlled for this in the analysis. It is important to recognize that there is no way to accurately estimate response rate. It is difficult to know how many coordinators who received the email actually opened it. Similarly, we cannot know how many sent to their residents. Assuming that every OBGYN resident in the United States and Puerto Rico received the survey, the 
overall response rate was $8.1 \%(417 / 5,148)$. However, though our sample size is relatively small, it does represent the largest sample to date. It should also be noted that other published studies of the impact of OBGYN fellows in other subspecialties are all smaller in size. ${ }^{3,7}$

\section{Conclusion}

In conclusion, this study found that the presence of MFM fellows does not appear to impact the comfort levels of graduating residents in performing complex obstetric procedures. Though experiences with VAVD may come earlier when MFM fellows are not present, by graduation, residents report no differences comfort performing some form of operative vaginal delivery, or with any other complex obstetric procedure after graduation, based on the presence of MFM fellows during their residency training. Also importantly, MFM fellows were overwhelmingly noted to have a positive impact on resident learning. Maybe it is time to consider the positives of training in programs with fellows! The narrative that fellows "steal" is somewhat based in fear and anecdote. Maybe the opposite is true!

\section{Prior Presentation}

This research was presented as a poster presentation at the 2019 ACOG national meeting in Nashville, TN.

Funding

None.

\section{Conflict of Interest}

None declared.

\section{References}

1 Grober ED, Elterman DS, Jewett MA. Fellow or foe: the impact of fellowship training programs on the education of Canadian urology residents. Can Urol Assoc J 2008;2(01):33-37

2 Potts JR III. Effect of new fellowship programs on resident case volume in pediatric surgery. J Am Coll Surg 2019;229(01):126-133

3 Propst K, Steinberg AC, O'Sullivan DM, Schimpf MO, LaSala C. Resident education in female pelvic medicine and reconstructive surgery. Female Pelvic Med Reconstr Surg 2017;23(04):263-266

4 Cohn DE, Roney JD, O'Malley DM, Valmadre S. Residents' perspectives on surgical training and the resident-fellow relationship: comparing residency programs with and without gynecological oncology fellowships. Int J Gynecol Cancer 2008;18(01):199-204

5 CREOG. Educational objectives: core curriculum in obstetrics and gynecology, 11th ed. Washington, DC: American College of Obstetricians and Gynecologists; 2016:48

6 The Obstetrics and Gynecology Milestone Project. The obstetrics and gynecology milestone project. J Grad Med Educ 2014;6(01, Suppl 1):129-143

7 Schimpf MO, Feldman DM, O'Sullivan DM, LaSala CA. Resident education and training in urogynecology and pelvic reconstructive surgery: a survey. Int Urogynecol J Pelvic Floor Dysfunct 2007;18(06):613-617

8 Gupta N, Dragovic K, Trester R, Blankstein J. The changing scenario of obstetrics and gynecology residency training. J Grad Med Educ 2015;7(03):401-406

9 Duffy JW III, Thomas JC, Makari JH, et al. The impact of a fellowship on resident training in an academic pediatric urology practice. J Urol 2008;179(02):720-723, discussion 723

10 Zyromski NJ, Torbeck L, Canal DF, Lillemoe KD, Pitt HA. Incorporating an HPB fellowship does not diminish surgical residents' HPB experience in a high-volume training centre. HPB (Oxford) 2010;12(02):123-128

11 Adhikari S, Raio C, Morrison D, et al. Do emergency ultrasound fellowship programs impact emergency medicine residents' ultrasound education? J Ultrasound Med 2014;33(06):999-1004

12 Backes CH, Reber KM, Trittmann JK, et al. Fellows as teachers: a model to enhance pediatric resident education. Med Educ Online 2011;16:16 